\title{
Novel steps forward in the histopathology of non-celiac gluten sensitivity
}

\author{
Giuseppe Losurdo ${ }^{1} \cdot$ Domenico Piscitelli ${ }^{2}$ Alfredo Di Leo ${ }^{1}$ (D)
}

Received: 29 May 2018 / Accepted: 7 June 2018 / Published online: 18 June 2018

(C) Springer-Verlag GmbH Germany, part of Springer Nature 2018

Dear Editor,

We read with great interest the brief report by Zanini et al. [1] published on your journal concerning the need to identify duodenal histological features in suspected non-celiac gluten sensitivity (NCGS) in order to provide new insights into this still undefined condition. Indeed, its diagnosis is currently based on clinical features and the double-blind placebocontrolled gluten challenge [2]. We fully agree with the authors that this diagnostic procedure has some limitations due to its complexity, which could hamper the adherence of the patients. On this basis, we agree with the opinion of Zanini et al. that research for additional biomarkers of NCGS is necessary and compulsory [3]. Therefore, histopathology could represent a very appealing field of study. In this regard, we recently demonstrated, by immunohistochemistry, a rise in CD117+ cells in the lamina propria of patients with NCGS [4]. CD117 may identify mast cells; consequently, this result seems to be in agreement with that of Zanini et al., who found, in most cases, an increase in eosinophil count (more than five eosinophils in the lamina propria per high power field) when compared to the control group, where this finding was absent. These findings seem to lead to a shared conclusion, which might support an additional hypothesis about NCGS pathogenesis: an allergic intolerance to foods other than wheat [5] or a sui generis derangement in immune response could underlie NCGS [6].

In conclusion, we believe that an accurate histological analysis of duodenal samples of NCGS patients could unveil new ideas for its diagnosis [7], but the road is still long, and multicenter blinded studies performed on large population samples are needed.

Alfredo Di Leo

alfredo.dileo@uniba.it

1 Section of Gastroenterology, Department of Emergency and Organ Transplantation, University of Bari, Bari, Italy

2 Section of Pathology, Department of Emergency and Organ Transplantation, University of Bari, Bari, Italy
Authors' contributions All the authors conceived the idea for the letter. G. Losurdo wrote the letter, and all the authors approved the final version of the manuscript.

\section{Compliance with ethical standards}

Conflict of interest The authors declare that they have no conflict of interest.

\section{References}

1. Zanini B, Villanacci V, Marullo M, Cadei M., Lanzarotto F., Bozzola A., Ricci C. (2018). Duodenal histological features in suspected nonceliac gluten sensitivity: new insights into a still undefined condition. Virchows Arch. doi: https://doi.org/10.1007/s00428-018-2346-9

2. Catassi C, Elli L, Bonaz B, Bouma G, Carroccio A, Castillejo G, Cellier C, Cristofori F, de Magistris L, Dolinsek J, Dieterich W, Francavilla R, Hadjivassiliou M, Holtmeier W, Körner U, Leffler D, Lundin K, Mazzarella G, Mulder C, Pellegrini N, Rostami K, Sanders D, Skodje G, Schuppan D, Ullrich R, Volta U, Williams M, Zevallos V, Zopf Y, Fasano A (2015) Diagnosis of non-celiac gluten sensitivity (NCGS): the Salerno experts' criteria. Nutrients 7(6):4966-4977

3. Ierardi E, Losurdo G, Piscitelli D, et al (2018). Biological markers for non celiac gluten sensitivity: a question awaiting for a convincing answer. Gastroenterolo Hepatol Bed Bench 2018 in press

4. Losurdo G, Piscitelli D, Pezzuto F et al (2017) T helper lymphocyte and mast cell immunohistochemical pattern in nonceliac gluten sensitivity. Gastroenterol Res Pract 2017:5023680

5. Carroccio A, Mansueto P, D'Alcamo A, Iacono G (2013) Non-celiac wheat sensitivity as an allergic condition: personal experience and narrative review. Am J Gastroenterol 108(12):1845-1852

6. Losurdo G, Giorgio F, Piscitelli D, Montenegro L, Covelli C, Fiore MG, Giangaspero A, Iannone A, Principi M, Amoruso A, Barone M, di Leo A, Ierardi E (2016) May the assessment of baseline mucosal molecular pattern predict the development of gluten related disorders among microscopic enteritis? World J Gastroenterol 22(35):80178025

7. Villanacci V, Lanzini A, Lanzarotto F, Ricci C (2013) Observations on the paper of Carroccio et al. "non-celiac wheat sensitivity diagnosed by double-blind placebo-controlled challenge: exploring a new clinical entity". Am J Gastroenterol 108(4):619-620 